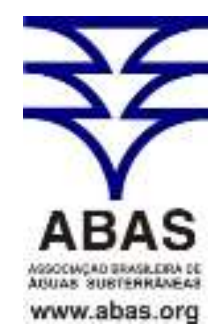

\section{CLASSIFICAÇÃO DO USO DA TERRA EM ÁREA DE AFLORAMENTO DO SISTEMA AQUÍFERO GUARANI ENTRE 2002 E 2011: O CASO DA BACIA DO RIBEIRÃO DO JACÚ, TEJUPÁ/SP}

\author{
LAND USE CLASSIFICATION AT GUARANI AQUIFER SYSTEM \\ OUTCROP AREA BETWEEN 2002 AND 2011: THE CASE OF RIBEI- \\ RÃO DO JACÚ WATERSHED TEJUPÁ/SP-BRAZIL
}

Artigo recebido em: 17/09/2015 e aceito para publicação em: 13/06/2016. DOI: http://dx.doi.org/10.14295/ras.v30i2.28512

\begin{abstract}
Resumo: Com a crescente demanda por recursos naturais que acompanha o crescimento populacional, o esforço para se oferecer água suficiente para a agricultura provoca pressões sobre o meio ambiente. Interesses conflitantes entre o uso da água e a proteção de mananciais estratégicos em áreas de proteção ambiental reforçam a necessidade da adequação e ordenamento do território visando o manejo sustentável dos recursos hídricos. O objetivo deste trabalho foi mapear o uso da terra em área de afloramento do Sistema Aquífero Guarani (SAG) e gerar informações para discutir ações para um melhor planejamento do uso da terra pela agricultura para conservação dos recursos hídricos subterrâneos em áreas de produção. A área de estudo foi a Bacia do Ribeirão do Jacú, localizada no município de Tejupá - SP, uma área representativa de afloramento do SAG e inserida no perímetro Tejupá da Área de Proteção Ambiental Corumbataí-Botucatu-Tejupá, região considerada altamente vulnerável. Com a classificação supervisionada do uso da terra em um Sistema de Informações Geográficas, pode-se identificar e quantificar as principais atividades desenvolvidas e os conflitos de uso da terra na bacia entre os anos de 2002 e 2011. Os resultados demonstram a apropriação de sistemas agrícolas e pecuária em Área de Preservação Permanente e avanço da agricultura irrigada, apontando tendência de intensificação da produção local. Essas informações contribuem para auxiliar futuras etapas de planejamento ambiental por gestores ambientais, visando a recuperação e preservação de zonas de afloramento e recarga do aquífero.
\end{abstract}

Palavras-chave: Interesses Conflitantes por Recursos Hídricos. Área de Proteção Ambiental (APA). Área de Preservação Permanente (APP). Sistema de Informações Geográficas (SIG).

\begin{abstract}
With the increasing demand for natural resources that follows population growth, the effort to provide sufficient water for agricultural proposes causes pressure on the environment. The conflicting interests between water use and the protection of strategic water bodies in environmental protection areas reinforce the needs for adjustments on territorial organization and sustainable water resources management. This study is intended to map land use in an outcrop area of the Guarani Aquifer System (GAS) and generate information to discuss better agricultural land use planning actions for groundwater resources conservation in production areas. The study area was the Ribeirão do Jacú watershed, located in Tejupá - SP, Brazil, a representative outcrop area of GAS inside the Tejupá perimeter of the Corumbataí-Botucatu-Tejupá EPA (Environmental Protection Area), considered a high vulnerability region. From land use and occupation supervised satellite image classification at Geographic Information System, it was possible to identify and to quantify the major activities developed and the actual land use conflicts in the watershed during the period between 2002 and 2011. The results showed the presence of agricultural and livestock systems in Permanent Preservation Areas (PPA's) and a raise of irrigated agriculture in areas closed to the outflow of the basin, indicating a trend of local production intensification. This information contributes to assisting future stages of environmental planning by environment and water managers, promoting the recovery and preservation of outcrop and recharge aquifer areas.
\end{abstract}

Keywords: Conflicting Claims for Water Resources, Environmental Protection Area (EPA). Permanent Protection Area (PPA). Geographic Information System (GIS).

1 UNESP, Faculdades de Ciências Agronômicas (FCA), Programa de Pós-Graduação em Agronomia (Irrigação e Drenagem), Botucatu/SP. (joyce_reissler@hotmail.com)

2 UNESP, Campus de Ourinhos, Ourinhos/SP. (manzione@ ourinhos.unesp.br) 


\section{INTRODUÇÃO}

A escassez hídrica e sua consequente gestão se apresentam como um dos maiores desafios atuais da humanidade, dada a intrínseca relação entre água e a continuidade da vida na Terra. Sua contaminação e/ou ausência levam à redução dos espaços de vida, afetando os ecossistemas e ocasionando desequilíbrio e perda global da qualidade de vida (DOWBOR, 2005). Sua importância não se restringe apenas à sobrevivência dos seres vivos, mas também ao desenvolvimento de todas as atividades econômicas e produtivas.

A pressão pelo crescimento econômico e populacional levou a uma exploração inadequada dos recursos hídricos. Com o crescimento populacional, cresce também a demanda por água doce, principalmente pela agricultura, que é responsável por $72 \%$ do consumo total desse recurso no Brasil (ANA, 2015). A produção de alimentos apresenta uma elevada demanda hídrica e o esforço para oferecer água suficiente para a agricultura provoca uma enorme pressão sobre o meio ambiente (CHRISTOFIDIS, 1997). Neste cenário, o aproveitamento específico dos recursos hídricos subterrâneos tem ganhado destaque nos últimos anos (BRASIL, 2007), por ser uma boa opção quanto à qualidade e pela facilidade de obtenção em locais próximos às áreas de produção (REBOUÇAS, 2006).

Com o aumento da demanda e os consequentes impactos das atividades antrópicas, a quantidade e qualidade das águas subterrâneas têm sido alteradas. No entanto, problemas com o abastecimento de água não estão associados unicamente ao crescimento demográfico ou econômico desordenado, mas sim também pela gestão deficiente desse recurso, incluindo a falta de planejamento do uso da terra e a falta de informação sobre aptidão local, que aliada à poluição dos recursos existentes, resulta na crise atual da água (LOZANO, 2013).

A falta de planejamento do uso da terra e de um manejo adequado em áreas rurais, quando somados à compactação do solo pela pecuária, à drenagem de áreas úmidas, à excessiva irrigação agrícola, contaminação das águas e do solo pelo uso abusivo de agrotóxicos, superexploração dos aquíferos e a não preservação de matas ripárias, ameaçam de forma direta e indireta o recurso hídrico subterrâneo. O tipo e o uso da terra são fatores determinantes nos processos de filtragem e recarga das águas subterrâneas. O tipo de cultura desenvolvida em determinada área, bem como seus processos de produção, pode influenciar na quantidade e qualidade da água subterrânea (HEALY, 2010; SOUZA et al., 2004; TAVARES FILHO et al., 2001) pelas diferenças na evapotranspiração, profundidade de raízes, estrutura do solo e insumos utilizados (TANIKAWA e MANZIONE, 2011; VAERET et al., 2009; SCANLON et al., 2005), sendo mais relevante em áreas de afloramento por sua característica de vulnerabilidade.

Além disso, de acordo com Bezerra e Veiga (2000), o manejo inadequado do solo e o desmatamento acarretam em degradação da estrutura física do solo desencadeando processos de erosão. Os solos empobrecidos pelos processos erosivos requerem a adição de fertilizantes que, na maioria das vezes não suprem de modo natural as necessidades nutricionais das plantas, tornando-as suscetíveis a ataques de pragas e doenças, exigindo do agricultor a associação de fertilizantes e defensivos agrícolas. Esse ciclo, bastante comum na agricultura moderna, pode acarretar em uma série de impactos, em especial, aos recursos hídricos. O presente cenário torna-se ainda mais agravante em locais com ocorrência de afloramento e recarga direta de aquíferos, mais sensíveis à contaminação por agroquímicos.

As áreas de afloramento do Sistema Aquífero Guarani (SAG) constituem importantes entradas de água no sistema hídrico, sendo de fundamental importância para sua recarga. Essas áreas de recarga direta são regiões onde o Aquífero Guarani encontra-se mais frágil e, portanto, vulnerável (IRITANI e EZAKI, 2008) e o mau uso da terra pode comprometer a qualidade da água.

Com a recente crise hídrica no Estado de São Paulo pela forte estiagem (COELHO et al., 2015), coloca-se em evidência a necessidade urgente de preservação dos recursos naturais, principalmente em áreas de alta vul- 
nerabilidade, para a manutenção econômica e da qualidade social. A intensificação da agricultura e pecuária em áreas de afloramento e recarga do aquífero pode colocar em risco a disponibilidade de água (LUCAS e WENDLAND, 2016). A destruição de áreas importantes de floresta pode diminuir a capacidade de armazenamento da bacia com consequentemente interferência na vazão em períodos de seca (LIMA e ZAKIA, 2009). Proteger e recuperar mananciais são ações importantes para amenizar problemas futuros de abastecimento de água e garantir a segurança hídrica em situações de estresse, sem o perigo de se chegar ao esgotamento dos mananciais e assegurando a conservação em áreas vulneráveis da manutenção da qualidade e quantidade dos recursos hídricos.

A gestão com responsabilidade do uso da terra e atividades agrícolas conscientes podem contribuir fortemente para a segurança dos recursos hídricos e da economia no futuro, já que a indisponibilidade de água prejudica o funcionamento de diversas atividades econômicas. $\mathrm{O}$ uso adequado da terra é o primeiro passo em direção ao desenvolvimento econômico sustentável das atividades agrícolas e segurança hídrica, assim, deve-se empregar cada parcela de terra de acordo com a sua aptidão, capacidade de sustentação e produtividade econômica, de tal forma que os recursos naturais sejam colocados à disposição do homem para seu melhor uso e benefício e preservados para gerações futuras (LEPSCH et al., 1991). Adequar a atividade humana em função da capacidade de suporte do meio é fazer uma parceria com as características naturais do terreno para uma ocupação ambientalmente responsável (HIRATA, 1994). Logo, torna-se fundamentalmente necessário caracterizar as diferentes coberturas e uso da terra a fim de gerar uma gestão eficiente do recurso hídrico subterrâneo, prover políticas públicas que incentivem o planejamento pela agricultura e oferecer oportunidades para o uso sustentável.

Tundisi e Matsumura-Tundisi (2008) acentuam que uma base de dados que gere informação, transformada em instrumento de gestão, pode ser uma das formas mais eficazes de enfrentar o problema de escassez de água, estresse e deterioração da sua qualidade. Assim, é imprescindível o desenvolvimento de trabalhos científicos que caracterizem áreas de fragilidade de aquíferos e criem propostas de gestão que garantam a integridade desse recurso, quantidade e qualidade de água seguras para as futuras gerações. Ferramentas de geoprocessamento como os Sistemas de Informações Geográficas (SIG) permitem elaborar mapas e exibir cenários facilitando a compreensão da cobertura e uso da terra para o seu melhor aproveitamento de forma responsável (BORGES, 2008; RODRIGUEZ, 2005).

Diante desse contexto, o presente estudo teve como objetivo o mapeamento do uso da terra em área de afloramento do SAG, classificando as culturas agrícolas presentes e identificando os possíveis conflitos de uso da terra em uma bacia hidrográfica localizada no município de Tejupá - SP. Essas informações são subsídios para um melhor planejamento e discussão de ações para a conservação dos recursos hídricos subterrâneos em áreas de produção agrícola localizados em área de proteção ambiental (APA), e uma contribuição sobre o perfil de uso da terra em áreas de afloramento do SAG como auxílio aos planos já existentes de proteção ambiental no Estado de São Paulo e no perímetro da APA Corumbataí-Botucatu-Tejupá como um todo.

\section{MATERIAL E MÉTODOS}

\section{1 Área de estudo}

A área de estudo compreende a Bacia do Ribeirão do Jacú, afluente à margem esquerda do Rio Paranapanema à jusante da Represa Jurumirim. A bacia está localizada no município de Tejupá (Lat.: 23²0'S; Long.: $49^{\circ} 22^{\prime} \mathrm{W}$; Alt.: 765 m a.n.m.), região sudoeste do Estado de São Paulo e está inserida na Unidade de Gerenciamento de Recursos Hídricos $\mathrm{n}^{\circ} 14$ (UGRHI-14), correspondente à Bacia Hidrográfica do Alto Paranapanema (Figura $1)$. 


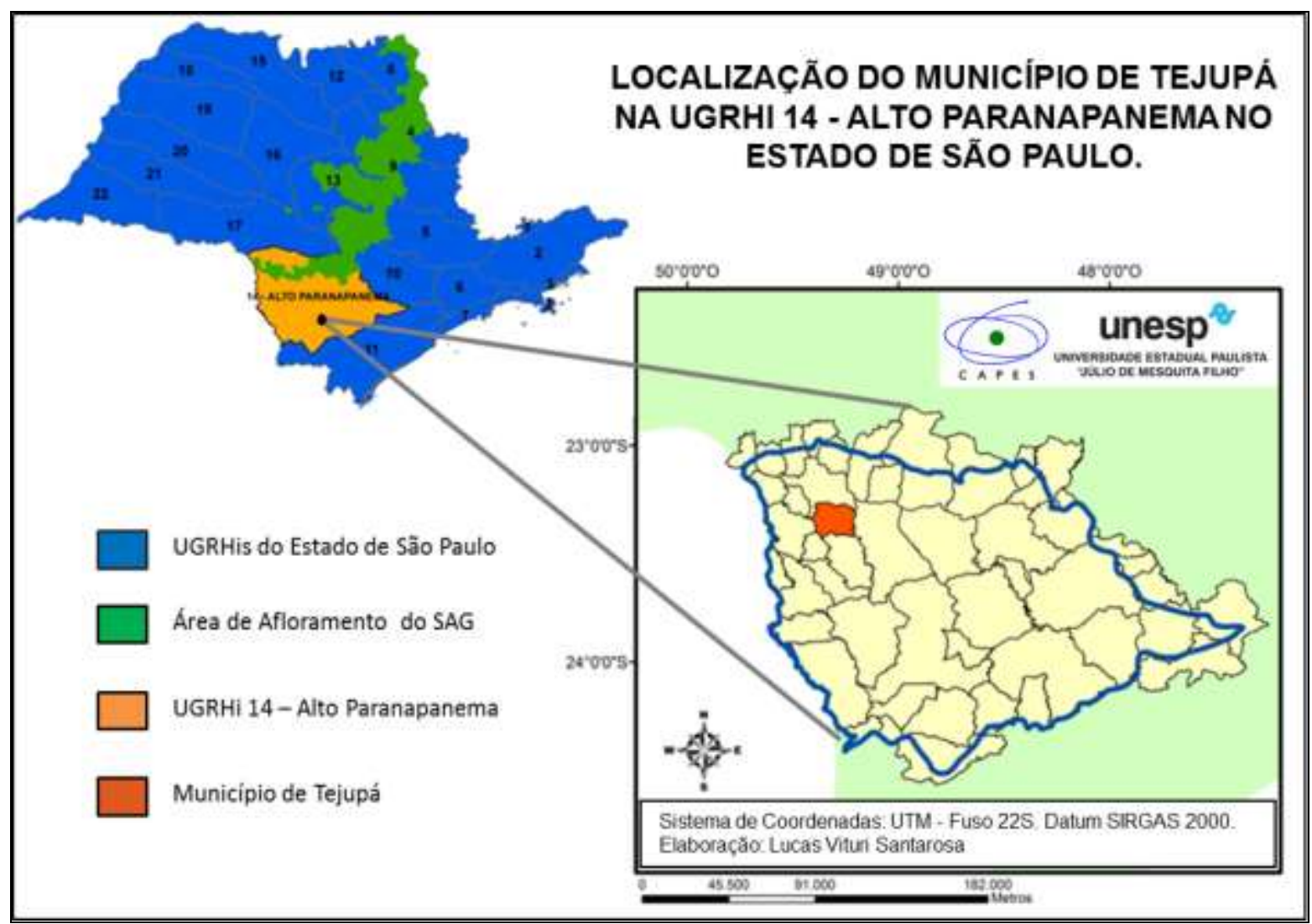

Figura 1 - Localização do município de Tejupá-SP na UGRHI 14 (Alto Paranapanema) Figure 1 - Municipality of Tejupá-SP, Brazil location at UGRHI 14 (Alto Paranapanema)

Conforme o Relatório Síntese do Plano de Desenvolvimento e Proteção Ambiental da Área de Afloramento do Sistema Aquífero Guarani (PDPA-SAG), proposto por Albuquerque Filho et al. (2011), o município de Tejupá está inserido em área delimitada como de proteção ao afloramento do Aquífero Guarani. O manejo e uso inadequado da terra pode exercer forte pressão sobre os recursos hídricos superficiais, dentre eles o Ribeirão do Jacú e, subterrâneos, que neste caso poderá comprometer a integridade do SAG. Segundo Albuquerque Filho et al. (2011), o índice de vulnerabilidade natural do SAG à contaminação para o município de Tejupá utilizando o método GOD é de médio a alto, salientando que em algumas partes do município o índice não foi definido por insuficiência de informações para aplicação do método.

Considerando que esta região é de grande potencial agrícola - incluindo culturas irrigadas como milho, soja e café - que de- mandam diversas aplicações anuais de agrotóxicos, são necessárias medidas conservacionistas que associem a produção local com boas práticas de uso e manejo da terra, recuperação de áreas sensíveis e proteção dos recursos hídricos superficiais e subterrâneos, principalmente em áreas de vulnerabilidade do SAG.

De acordo com o Mapa Geomorfológico do Estado de São Paulo elaborado por Ross e Moroz (1996), a Bacia do Ribeirão do Jacú pertence à região da depressão do Paranapanema, parte da Bacia Sedimentar do Paraná, apresentando calhas com topos convexos, altimetria entre 600 e 700 metros e declividade dominante entre 10 e $20 \%$.

A litologia local dominante é formada por arenitos e arenitos eólicos. Entretanto, a Bacia do Ribeirão do Jacú apresenta certas peculiaridades. A cabeceira da bacia encontra-se em região de falhamentos geológicos, resultando em um relevo bastante movimentado (IPT, 1974). Na região são encontradas rochas 
das formações Botucatu e Serra Geral (Figura 2). À margem esquerda os solos foram formados por basaltos toleíticos em derrames tabulares superpostos e arenitos intertrapianos. À margem direita encontram-se solos formados por arenitos finos a médios, com estratificação cruzada de grande porte e cores creme e vermelho, compondo principalmente Latos solos Vermelhos (LV47) e Latossolos Vermelho-Amarelos (LVA13) (OLIVEIRA et al., 1999). No exutório da bacia são encontrados diques e sills, em geral básicos, incluindo diabásios. A área está sujeita a processos erosivos agressivos com probabilidade de ocorrência de movimentos de massa e erosão linear com voçorocas.
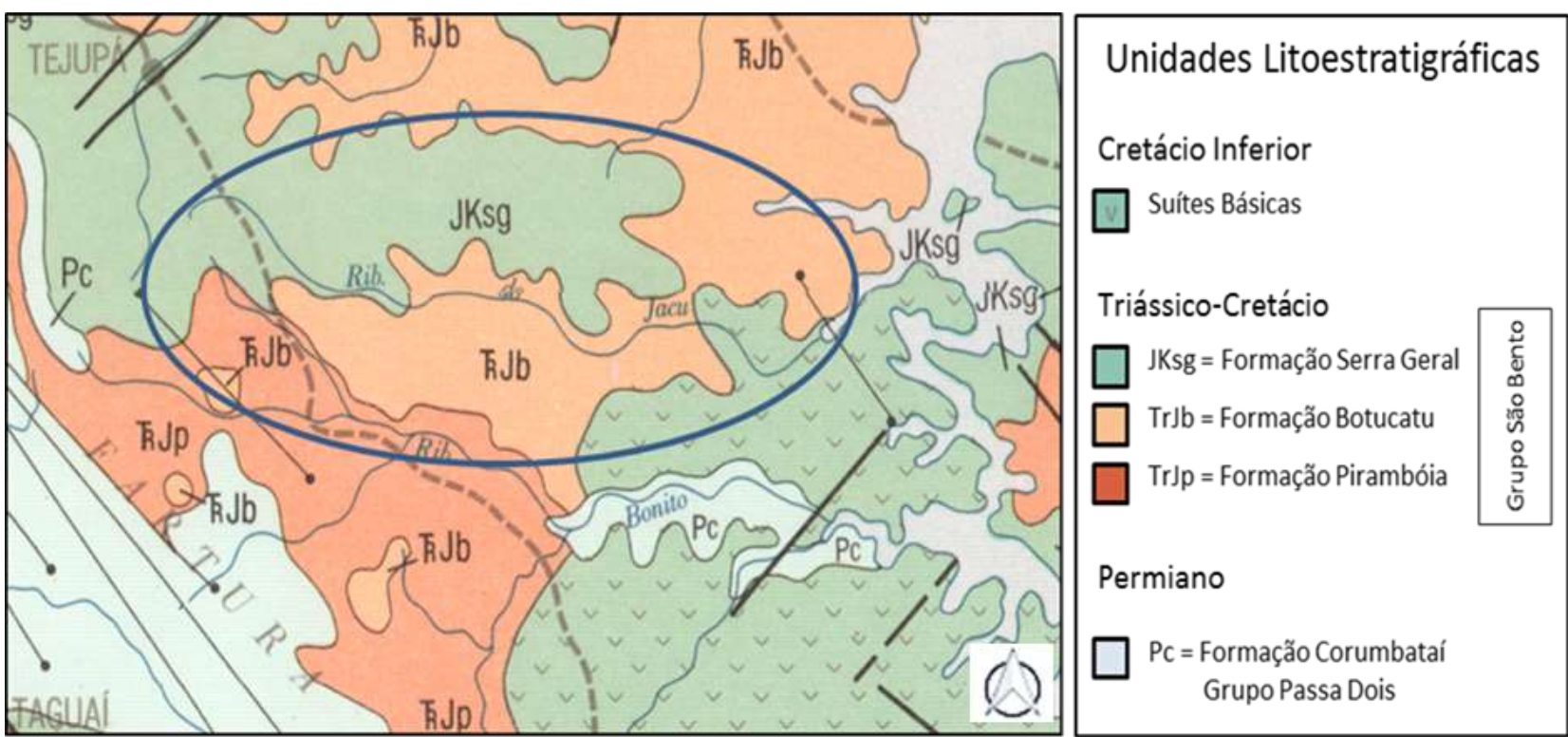

Figura 2 - Detalhe das feições geológicas da Bacia do Ribeirão do Jacú

Fonte: Mapa Geológico do Estado de São Paulo (Folha SF-22-Z-D/SF-22-Z-C)

Figure 2 - Detail of the Ribeirão do Jacú watershed geological features

Source: São Paulo State Geological Map (Sheet SF-22-Z-D/SF-22-Z-C)

O índice crescente de dissecação do relevo e fragilidade é o Dc 24 (ROSS e MOROZ, 1996), apresentando um nível de fragilidade potencial alto em razão de suas formas muito dissecadas com vales entalhados associados a vales pouco entalhados e alta densidade de drenagem.

Segundo a classificação climática de Köppen (1923), o clima da região é Cwa (clima tropical de altitude, com chuvas no verão e seca no inverno). A temperatura média anual é de $20,1^{\circ} \mathrm{C}$, oscilando entre mínima média de $13,9^{\circ} \mathrm{C}$ e máxima média de $26,3{ }^{\circ} \mathrm{C}$, e a precipitação pluvial média anual é de 1453,8 mm.

A Bacia do Ribeirão do Jacú, assim como todo município de Tejupá, faz parte do perímetro Tejupá da Área de Preservação Ambiental (APA) Corumbataí-Botucatu-Tejupá, criada através do Decreto Estadual $N^{\circ}$ 20.960 em 08 de junho de 1983. É uma área destinada a proteger áreas de afloramento do SAG, Cuestas Basálticas, Morros Testemunhos de feições geomorfológicas locais, maciços vegetacionais formadores do ecótono entre a fisionomia de domínio Mata Atlântica (Floresta Estacional Decidual e Semidecidual, Florestas Paludosas e Ripárias) e o Cerrado, que refletem grande riqueza e diversidade biológica. Esta unidade de conservação visa promover o desenvolvimento sustentável das atividades econômicas locais, identificação de remanescentes ou áreas de interesse para recuperação e conservação da biodiversidade, uma vez que a substituição de ambientes naturais por agrossistemas tem-se tornado cada vez mais comum, promovendo a supressão de florestas naturais e prejudicando seus serviços ecossistêmicos.

\subsection{Metodologia}


Para a produção dos mapas, o material cartográfico utilizado para compor a Bacia do Ribeirão do Jacú foram as cartas topográficas do IBGE na escala 1:50.000 de Sarutaiá (folha SF22ZDI3) e de Itaí (folha SF22ZDI4), em formato raster. Para o processo de classificação do uso da terra ao longo dos anos foram utilizadas as imagens datadas em 21/06/2002 (Landsat-7 ETM+) e 26/09/2011 (Landsat-5 TM) e o Sistema de Informações Geográficas (SIG) SPRING (CAMARA et al., 1996) versão 5.2.4. No SIG SPRING foi estruturado um banco de dados utilizando o gerenciador Acess e com dados projetados no Sistema Universal Transversa de Mercator (UTM), zona 22 Sul, em coordenadas planas e Datum SIRGAS 2000.

Nas cartas topográficas foram vetorizados os limites e rede de drenagem da Bacia do Ribeirão do Jacú de forma manual. As cartas também serviram como base para o processamento digital das imagens Landsat, na etapa de pré-processamento de transformação geométrica, no qual foram registrados 64 pontos de controle em modo teclado para a correção de possíveis distorções existentes nas imagens causadas em seu processo de formação pelo sensor e por imprecisão dos dados de posicionamento do satélite. Também com o objetivo de melhorar a qualidade visual das imagens e a interpretação da informação, utilizou-se a técnica de realce das imagens através do contraste linear, modificando a escala de cinza e os valores digitais para o destaque de certas informações espectrais e melhorar a qualidade visual do intérprete.

O processamento digital das imagens seguiu-se com a classificação das imagens, através da segmentação automática pelo agrupamento de pixels por crescimento de regiões, que consiste em agrupar pixels com características similares em termos tonais e texturais, formando regiões homogêneas onde cada área possui características espectrais bem diferentes das vizinhas que a cercam. Esse procedimento se baseia na descontinuidade e similaridade dos níveis de cinza da imagem, dividindo a imagem em regiões de pixels contíguos e uniformes por um critério de similaridade a cada par de região adjacente. A simila- ridade refere-se à proximidade radiométrica entre pixels pelo valor da distância euclidiana mínima entre as médias e o limiar de área é o número mínimo de pixels para que uma região seja individualizada. Após testes de eficiência, foram escolhidos a similaridade igual a 6 e número de pixels igual a 8 .

$\mathrm{Na}$ classificação por regiões da imagem segmentada, foi utilizado o classificador Batacharya para classificação supervisionada, que requer a seleção de amostras de treinamento utilizando as regiões separadas durante o processo de segmentação e que estima a função densidade. $\mathrm{O}$ procedimento de treinamento reconhece a assinatura espectral pela seleção de amostras (áreas) representativas de cada classe que se deseja identificar na imagem. A identificação das classes de uso foi realizada a partir da interpretação da imagem de satélite, considerando a resposta espectral imageada utilizando a composição colorida falsa-cor 5(R), 4(G) e 3(B) nas imagens para melhor discriminar os alvos analisados.

Para a Bacia do Ribeirão do Jacú, foram definidas nove classes de classificação com base no Manual Técnico do Uso da Terra (IBGE, 2013): Corpo d'água, Mata, Reflorestamento, Pastagem, Cultura permanente, Cultura temporária, Cultura irrigada, Erosão e Área construída. Como cultura irrigada, foi considerado o método de pivô central por ser facilmente identificado através das imagens aéreas e por ser a de maior expansão no país nos últimos anos.

Realizou-se um tratamento pós-classificação e edição matricial para corrigir pequenas confusões de classificação e refinar o resultado dos mapas temáticos. Toda a Bacia do Ribeirão do Jacú foi revisada e, quando necessário, foram feitas correções na classificação das diferentes classes, principalmente em suas bordas.

O nível de confiança da classificação foi verificado por meio da matriz de erros, que apresenta a distribuição de percentagem de "pixels" classificados correta e erroneamente e mostra o quanto o classificador de imagens confunde uma classe com a outra (CONGALTON e GREEN, 1998). A diagonal principal da matriz representa o número de pixels cor- 
retamente classificado de acordo com a verdade de campo, onde as linhas representam as classes da verdade terrestre e as colunas representam as classes do mapa obtido pela classificação. Pela matriz de erros, foi possível calcular, através do software SPRING, o índice de precisão da classificação total, o Índice Kappa (LANDIS e KOCK, 1977). O índice de exatidão Kappa considera a proporção de amostras corretamente classificadas pela razão entre a soma da diagonal principal da matriz de erros (amostras corretamente classificadas) e a soma de todos os elementos desta matriz (total de amostras), baseado no número total de classes.

Para a delimitação das Áreas de Preservação Permanente (APPs), foi elaborado um buffer padrão de 30 metros marginal ao leito dos rios juntamente com um raio de 50 metros para as nascentes, conforme legislação florestal vigente. Para cada início do vetor da hidrografia foi considerado como nascente. Por não ocorrer um levantamento histórico de ocupação e desenvolvimento de cada propriedade rural da bacia, não foi considerada uma menor área de preservação às áreas ditas como consolidadas.

\section{RESULTADOS E DISCUSSÕES}

Através da vetorização dos limites da bacia e de sua rede de drenagem, o Ribeirão do Jacú apresentou-se com 3.674 ha de área total da bacia, perímetro de $37,21 \mathrm{~km}$ e rede de drenagem com 54,03 km de extensão.

Para a classificação, foram coletadas 985 amostras de treinamento para 8 classes (média de 123 amostras por classe) pela imagem de 2002 e 1356 amostras de treinamento para 9 classes (média de 150 amostras por classe) pela imagem de 2011. De acordo com Congalton e Green (1998), o número de amostras por classe deve ser superior a 30 para que haja um desempenho adequado e confiável na classificação temática. Na avaliação estatística de desempenho da classificação, obteve-se na imagem de 2002 um desempenho geral de 99,12\% e índice Kappa de $98,84 \%$ e, na imagem de 2011 , o desempenho geral de $98,99 \%$ e índice Kappa de 98,75\% (Tabelas 1 e 2). De acordo com Landis e Koch (1977), conclui-se que as amostragens das imagens são enquadradas como excelentes.

Tabela 1 - Matriz de erros da classificação da imagem de uso da terra de 2002

Table 1 - Errors matrix from 2002 land use image classification

\begin{tabular}{|c|c|c|c|c|c|c|c|c|c|}
\hline \multicolumn{10}{|c|}{ Matriz de erros de classificação do ano de 2002} \\
\hline Classes & Cd & $\mathbf{M}$ & $\mathbf{P}$ & $\mathrm{Cp}$ & Ct & Ac & $\mathbf{R}$ & $\mathbf{E}$ & Soma \\
\hline Cd & 196 & 0 & 0 & 0 & 0 & 0 & 0 & 0 & 196 \\
\hline M & 0 & 9309 & 0 & 0 & 0 & 0 & 0 & 0 & 9309 \\
\hline $\mathbf{P}$ & 0 & 93 & 12178 & 0 & 0 & 0 & 0 & 0 & 12271 \\
\hline Cp & 0 & 22 & 32 & 7533 & 0 & 0 & 0 & 0 & 7587 \\
\hline Ct & 0 & 0 & 226 & 0 & 11431 & 0 & 0 & 0 & 11657 \\
\hline Ac & 0 & 0 & 0 & 0 & 0 & 532 & 0 & 0 & 532 \\
\hline $\mathbf{R}$ & 0 & 0 & 0 & 0 & 0 & 0 & 742 & 0 & 742 \\
\hline E & 0 & 0 & 0 & 0 & 0 & 0 & 0 & 13 & 13 \\
\hline Soma & 196 & 9424 & 12436 & 7533 & 11431 & 532 & 742 & 13 & 42307 \\
\hline \multicolumn{10}{|c|}{ Acurácia } \\
\hline DG & & & & 99, & $2 \%$ & & & & \\
\hline $\mathbf{K}$ & & & & 98 & $34 \%$ & & & & \\
\hline
\end{tabular}

Valores em pixels. Cd: Corpo d'água; M: Mata; P: Pastagem; Cp: Cultura permanente; Ct: Cultura temporária; Ac: Área construída; R: Reflorestamento; E: Erosão; DG: Desempenho geral; K: Índice Kappa.

Values in pixels. Cd: Water body; M: Forest; P: Pasture; Cp: Permanent agriculture; Ct: Temporary agriculture; Ac: Constructed area; R: Reforest; E: Erosion; DG: General performance; K: Kappa index. 
Tabela 2 - Matriz de erros da classificação da imagem de uso da terra de 2011

Table 2 - Errors matrix from 2011 land use image classification

\begin{tabular}{|c|c|c|c|c|c|c|c|c|c|c|}
\hline \multicolumn{11}{|c|}{ Matriz de erros de classificação do ano de 2011} \\
\hline Classes & Cd & $\mathbf{M}$ & $\mathbf{P}$ & $C p$ & Ac & Ct & $\mathbf{R}$ & $\mathbf{C i}$ & $\mathbf{E}$ & Soma \\
\hline Cd & 159 & 0 & 0 & 0 & 0 & 0 & 0 & 0 & 0 & 159 \\
\hline $\mathbf{M}$ & 0 & 7724 & 0 & 0 & 0 & 0 & 0 & 0 & 0 & 7724 \\
\hline $\mathbf{P}$ & 0 & 116 & 10387 & 0 & 0 & 0 & 0 & 0 & 0 & 10503 \\
\hline $\mathrm{Cp}$ & 0 & 0 & 88 & 7765 & 0 & 0 & 0 & 0 & 0 & 7853 \\
\hline $\mathbf{A C}$ & 0 & 0 & 101 & 0 & 925 & 0 & 0 & 0 & 0 & 1026 \\
\hline $\mathbf{C t}$ & 0 & 0 & 23 & 0 & 0 & 9003 & 0 & 0 & 0 & 9026 \\
\hline $\mathbf{R}$ & 0 & 27 & 0 & 0 & 0 & 0 & 2908 & 0 & 0 & 2935 \\
\hline $\mathbf{C i}$ & 0 & 0 & 0 & 0 & 0 & 0 & 0 & 2122 & 0 & 2122 \\
\hline $\mathbf{E}$ & 0 & 0 & 0 & 0 & 0 & 67 & 0 & 0 & 50 & 117 \\
\hline Soma & 159 & 7867 & 10599 & 7765 & 925 & 9070 & 2908 & 2122 & 50 & 41465 \\
\hline \multicolumn{11}{|c|}{ Acurácia } \\
\hline \multicolumn{11}{|c|}{$99,12 \%$} \\
\hline K & & & & & $98,84^{\circ}$ & & & & & \\
\hline
\end{tabular}

Valores em pixels. Cd: Corpo d'água; M: Mata; P: Pastagem; Cp: Cultura permanente; Ct: Cultura temporária; Ac: Área construída; R: Reflorestamento; Ci: cultura irrigada; E: Erosão; DG: Desempenho geral; K: Índice Kappa.

Values in pixels. Cd: Water body; M: Forest; P: Pasture; Cp: Permanent agriculture; Ct: Temporary agriculture; Ac: Constructed area; R: Reforest; Ci, Irrigated agriculture; E: Erosion; DG: General performance; K: Kappa index.

De acordo com a classificação supervisionada das imagens do satélite Landsat de 2002 e 2011, foram gerados valores represen-

tativos das áreas de cada classe de uso da terra na Bacia do Ribeirão do Jacú (Tabela 3 e Figuras 3 e 4$)$.

Tabela 3 -Área (ha e \%) das classes de uso da terra na Bacia do Ribeirão do Jacú e suas variações entre os anos de 2002 e 2011

Table 3 - Land use classes area (ha and \%) at Ribeirão do Jacú watershed and its variations between the years of 2002 and 2011

\begin{tabular}{ccccccc}
\hline \multirow{2}{*}{ Classes } & \multicolumn{2}{c}{$\mathbf{2 0 0 2}$} & \multicolumn{2}{c}{$\mathbf{2 0 1 1}$} & \multirow{2}{*}{ DP (\%) } & VA \\
\cline { 2 - 5 } & ha & $\mathbf{\%}$ & ha & \% & & \\
\hline Corpo d'água & 17,46 & 0,47 & 15,29 & 0,41 & $-0,06$ & 2,17 \\
Mata & 710,82 & 19,27 & 539,09 & 14,61 & $-4,66$ & 171,73 \\
Reflorestamento & 66,51 & 1,80 & 327,51 & 8,88 & 7,08 & 261,00 \\
Pastagem & $1.065,60$ & 28,89 & $1.037,27$ & 28,12 & $-0,77$ & 28,33 \\
Cultura permanente & 776,97 & 21,06 & 721,98 & 19,57 & $-1,49$ & 54,99 \\
Cultura temporária & $1.012,59$ & 27,45 & 911,25 & 24,70 & $-2,75$ & 101,34 \\
Cultura irrigada & 0,00 & 0,00 & 95,76 & 2,60 & 2,60 & 95,76 \\
Erosão & 1,53 & 0,04 & 0,00 & 0,00 & $-0,04$ & 1,53 \\
Área construída & 37,44 & 1,01 & 40,77 & 1,11 & 0,09 & 3,33 \\
\hline Total & $3.688,92$ & 100 & $3.688,92$ & 100 & - & - \\
\hline
\end{tabular}

DP: diferença percentual entre os anos de 2002 e 2011; VA: variação absoluta (em ha)

PD: percentage difference between the tears of 2002 e 2011; AV: absolute variation (ha) 


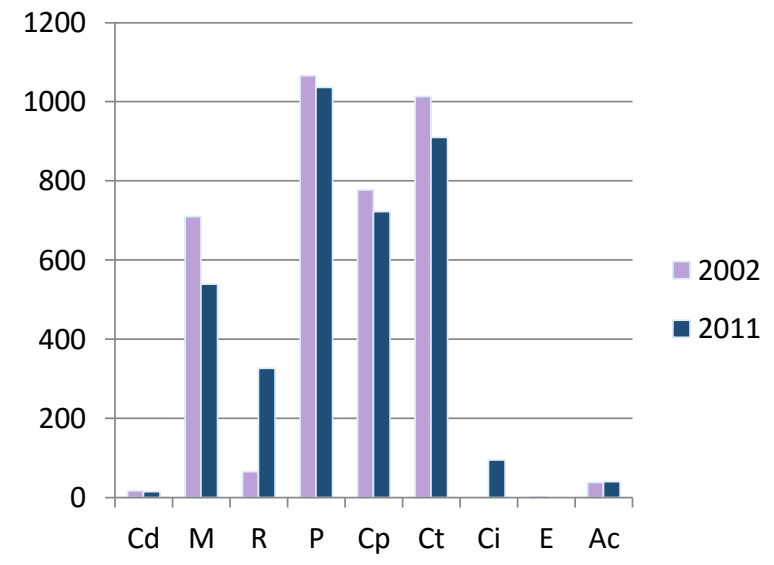

Figura 3 - Área (ha) das classes de uso da terra na Bacia do Ribeirão do Jacú em 2002 e 2011. Cd: Corpo d'água; M: Mata; R: Reflorestamento; P: Pastagem; Cp: Cultura permanente; $\mathrm{Ct}$ : Cultura temporária; $\mathrm{Ci}$ : Cultura irrigada; E: Erosão; Ac: Área construída.

Figure 3 - Land use classes area (ha) at Ribeirão do Jacú watershed at 2002 and 2011. Cd: Water body; M: Forest; R: Reforest; P: Pasture; Cp: Permanent agriculture; $\mathrm{Ct}$ : Temporary agriculture; $\mathrm{Ci}$ : Irrigated agriculture; E: Erosion; Ac: Constructed area.

A partir dos resultados exibidos na Tabela 3 pode-se observar que no ano de 2002 as classes mais representativas da bacia foram consideradas as de atividades antrópicas, sendo a de maior área a classe de pastagem, ocupando 28,89\% (1.065,60 ha) da área total da bacia, seguida pela cultura temporária com $27,45 \%$ (1.012,59 ha) e cultura permanente com 21,06\% (776,97 ha). Esses índices demonstram que a Bacia do Ribeirão do Jacú, em 2002, caracterizava-se fortemente pela atividade agropecuária. A classe que tipifica a mata natural ou em regeneração avançada ocupa o quarto lugar em maior área, representando $19,27 \%$ (710,82 ha) da área total em 2002. As classes corpo d'água, reflorestamento, área construída e erosão contribuíram com as menores representatividades na bacia. Neste ano analisado, não houve ocorrência da cultura irrigada.

Em 2011, as classes mais representativas da bacia, assim como em 2002, também foram as consideradas de atividades antrópicas. A classe pastagem foi a mais representativa da bacia, com $28,12 \%(1.037,27 \mathrm{ha}) \mathrm{da}$ área total, seguida pela cultura temporária com $24,70 \%(911,25 \mathrm{ha})$ e cultura permanente com $19,57 \%$ (721,98 ha).

Concordando com o ano de 2002, a

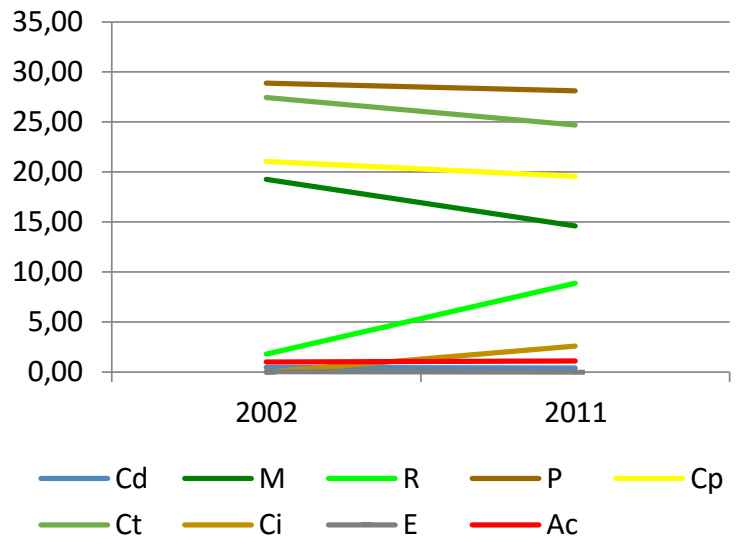

Figura 4 - Porcentagem do uso da terra na Bacia do Ribeirão do Jacú em 2002 e 2011. Cd: Corpo d'água; M: Mata; R: Reflorestamento; P: Pastagem; Cp: Cultura permanente; $\mathrm{Ct}$ : Cultura temporária; $\mathrm{Ci}$ : Cultura irrigada; E: Erosão; Ac: Área construída.

Figure 4 - Land use percentages at Ribeirão do Jacú watershed at 2002 and 2011. Cd: Water body; M: Forest; R: Reforest; P: Pasture; Cp: Permanent agriculture; $\mathrm{Ct}$ : Temporary agriculture; $\mathrm{Ci}$ : Irrigated agriculture; E: Erosion; Ac: Constructed area.

classe mata ocupa o quarto lugar em maior área, representando 14,61\% (539,09 ha) da área total. As classes menos representativas, em ordem decrescente, foram: reflorestamento, cultura irrigada, área construída e corpo d'água. No ano de 2011, não houve ocorrência da classe erosão.

Quando comparado os anos de 2002 e 2011, embora a permanência do padrão de grande representatividade das classes pastagem, cultura temporária e cultura permanente, é possível observar que, ao longo dos anos, há uma leve queda na porcentagem de área que elas ocupam na bacia $(-0,77 \%,-2,75 \%$ e $1,49 \%$, respectivamente). A variação absoluta dessas classes representa uma diminuição de 101,34 ha de culturas temporárias, 54,99 ha de cultura permanente e 28,33 ha de pastagens. Pode-se também observar uma significativa alteração na área das matas que teve a sua contribuição relativa na ocupação da terra na bacia diminuída em 4,66\% entre os anos de 2002 e 2011, representando uma diminuição de 171,73 ha, apesar de toda legislação e fiscalização incidentes. Comparando os anos, a diminuição na área de matas foi de $24,16 \%$. A redução destas classes pode ser explicada pela expansão das atividades de reflorestamento.

De acordo com a Tabela 3, o reflores- 
tamento conta com um expressivo aumento de sua área dentro da bacia, com uma diferença de percentual de $7,08 \%$ e apresentando uma variação absoluta de 261 ha entre os anos estudados, também podendo-se concluir que entre 2002 e 2011 o aumento na classe Reflorestamento foi de $392,42 \%$ na bacia do Ribeirão do Jacú. Já a ocorrência da classe cultura irrigada por pivô central é nula em 2002 e em 2011 é de 2,60\%, ocupando um espaço de 95,76 ha.

Mesmo apresentando variações de área das classes corpo d'água $(-12,43 \%)$ e área construída $(+8,89 \%)$, quando comparadas suas ocorrências na bacia nos anos de 2002 e 2011, essas variações não apresentam como relevantes na dinâmica do uso da terra no período estudado. Já a classe erosão detectada em 2002 não foi evidente na imagem de 2011, o que sugere uma amenização desse impacto no período estudado, tendo sido recuperada para o plantio de cana-de-açúcar.
Dentre os principais cultivos identificados na Bacia do Ribeirão do Jacú ocorrem o predomínio da cafeicultura e grandes áreas de cultivo de milho e soja, como também a atividade pecuária, que extendem-se por toda a bacia. Ocorrem também o cultivo da canade-açúcar e diversas áreas de reflorestamento, indicando o fortalecimento dessa atividade. Ganha-se destaque na região o aparecimento de pivôs central de irrigação por aspersão, o que denota o avanço de cultivos modernos e, assim, intensivos.

A alteração dos valores de classes entre os anos de 2002 e 2011 indica a dinâmica no cenário de ocupação da Bacia do Ribeirão do Jacú, que podem ser melhor observados através dos mapas elaborados (Figuras 5 e 6). Entre 2002 e 2011, sofreram diminuição as áreas de Pastagens $(-2,66 \%)$, Culturas permanentes $(-7,08 \%)$ e Culturas temporárias ($10,01 \%)$.

Figura 5 - Uso da terra no ano de 2002 na Bacia do Ribeirão do Jacú

Figure 5 - Land use in 2002 at Ribeirão do Jacú watershed

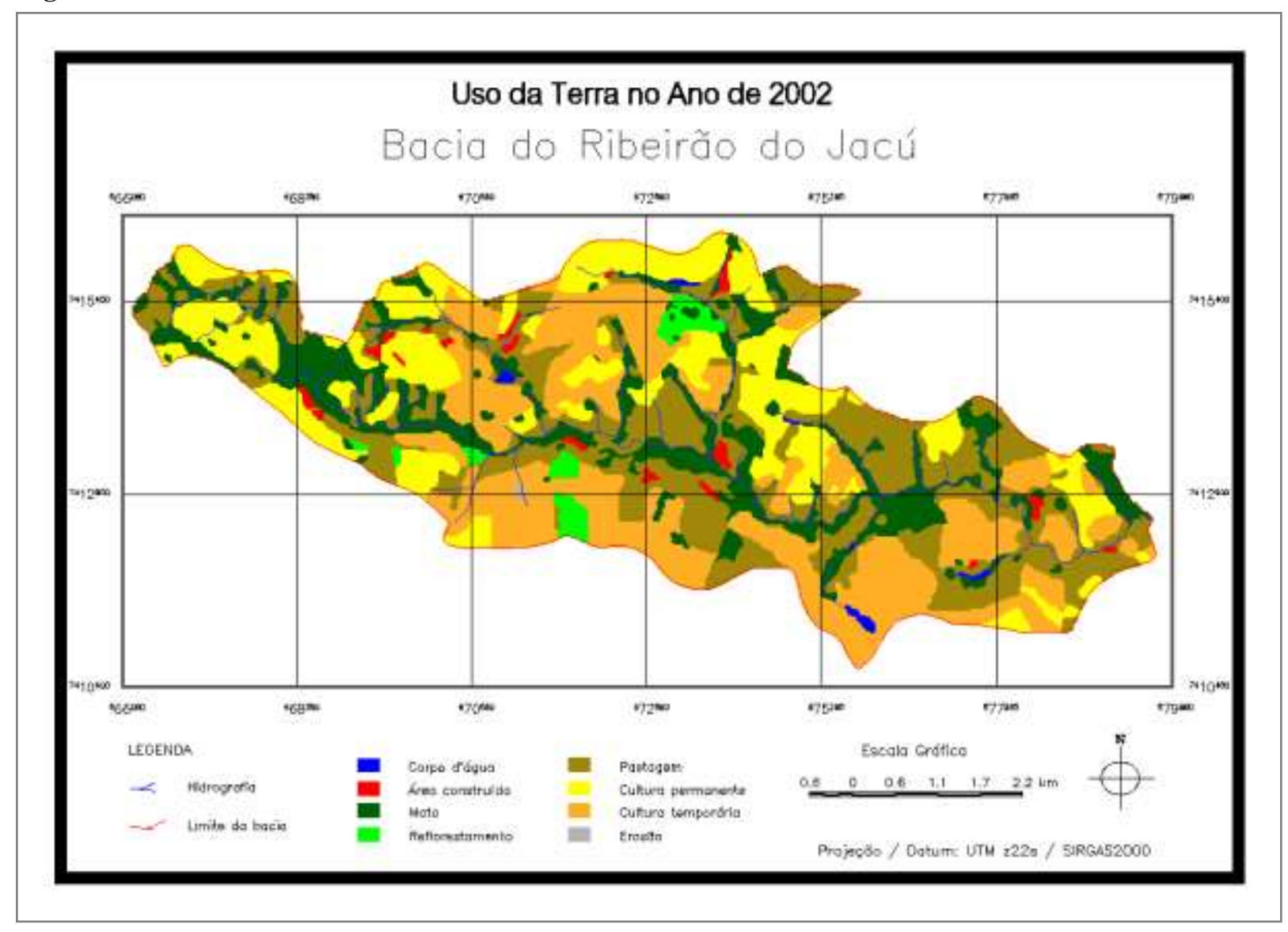


Nos mapas também é possível observar que tanto as diversas culturas, como a atividade de pecuária e reflorestamento ocupam áreas denominadas como de Áreas de Preservação Permanente (APPs), áreas essenciais para a manutenção da saúde ambiental dos recursos hídricos e resiliência da bacia hidrográfica. Áreas como esta contribuem para o aumento da capacidade de armazenamento e manutenção da qualidade da água, mantém a estabilidade das margens dos rios, provém equilíbrio térmico da água, a proteção de nascentes, formação de corredores ecológicos e a conservação da biodiversidade (FAIL et al., 1987; LIMA e ZAKIA, 2006; LOWRANCE et al., 1997; NAIMAN e DÉCAMPS, 1997).

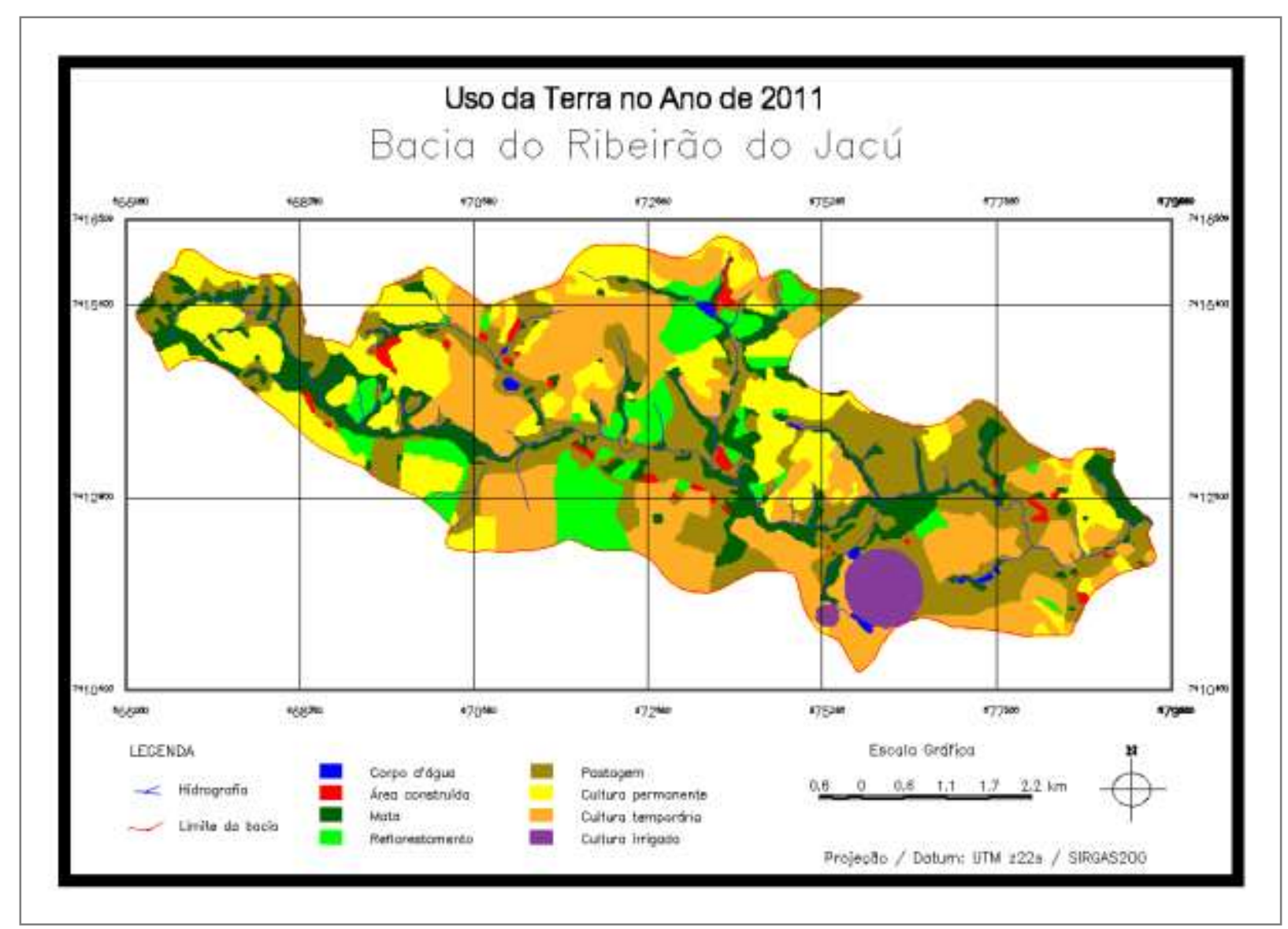

Figura 6 - Uso da terra no ano de 2011 na Bacia do Ribeirão do Jacú Figure 6 - Land use in 2011 at Ribeirão do Jacú watershed

A Bacia do Ribeirão do Jacú possui 336,98 ha de APP (nascentes e margens de rios), o que representa $9,17 \%$ da área total da bacia. Nesta área constatam-se conflitos de uso e preservação, como é possível observar na Tabela 4 e nas Figuras 7 e 8. 
Tabela 4 - Área (ha e \%) das classes de uso da terra em APP na Bacia do Ribeirão do Jacú e suas variações entre os anos de 2002 e 2011

Table 4 - Land use classes area (ha and \%) at PPA in the Ribeirão do Jacú watershed and its variations between the years of 2002 and 2011

\begin{tabular}{ccccccc}
\hline Classes & \multicolumn{2}{c}{$\mathbf{2 0 0 2}$} & \multicolumn{2}{c}{$\mathbf{2 0 1 1}$} & DP (\%) & VA \\
& ha & \% & ha & \% & & \\
\hline Corpo d'água & 4,68 & 1,18 & 3,42 & 0,86 & $-0,32$ & 1,26 \\
Mata & 208,80 & 52,58 & 158,85 & 40,00 & $-12,58$ & 49,95 \\
Reflorestamento & 0,54 & 0,14 & 27,63 & 6,96 & 6,82 & 27,09 \\
Pastagem & 131,31 & 33,07 & 143,82 & 36,22 & 3,15 & 12,51 \\
Cultura permanente & 27,72 & 6,98 & 35,73 & 9,00 & 2,02 & 8,01 \\
Cultura temporária & 22,32 & 5,62 & 25,56 & 6,44 & 0,82 & 3,24 \\
Cultura irrigada & 0,00 & 0,00 & 0,18 & 0,05 & 0,05 & 0,18 \\
Erosão & 0,45 & 0,11 & 0,00 & 0,00 & $-0,11$ & 0,45 \\
Área construída & 1,26 & 0,32 & 1,89 & 0,48 & 0,16 & 0,63 \\
Total & 397,08 & 100 & 397,08 & 100 & - & - \\
\hline
\end{tabular}

DP: diferença percentual entre os anos de 2002 e 2011; VA: variação absoluta (em ha).

PD: percentage difference between the tears of 2002 e 2011; AV: absolute variation (ha).

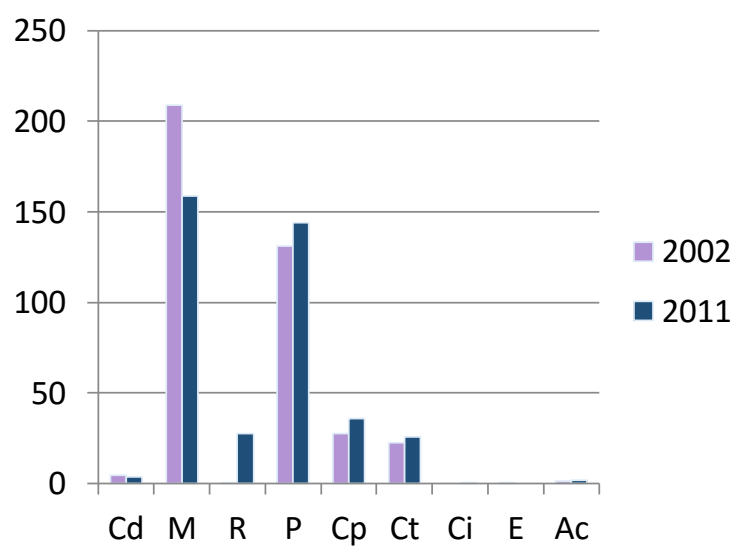

Figura 7 - Gráfico da área (em ha) das classes de uso da terra na Bacia do Ribeirão do Jacú no ano de 2002 e 2011. Cd: Corpo d'água; M: mata; R: reflorestamento; P: pastagem; Cp: cultura permanente; $\mathrm{Ct}$ : cultura temporária; $\mathrm{Ci}$ : cultura irrigada; E: erosão Ac: área construída.

Figure 7 - Area (ha) graphic of land use classes at Ribeirão do Jacú watershed at 2002 and 2011. Cd: Water body; M: Forest; R: Reforest; P: Pasture; Cp: Permanent agriculture; $\mathrm{Ct}$ : Temporary agriculture; $\mathrm{Ci}$ : Irrigated agriculture: E: Erosion: Ac: Constructed area.

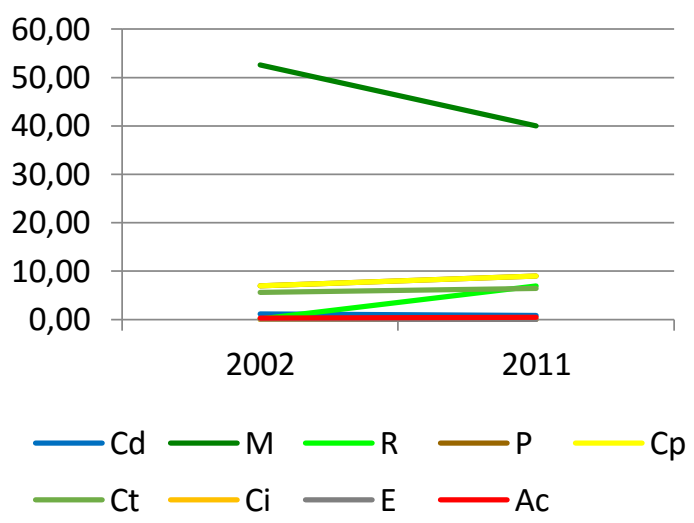

Figura 8 - Uso da terra em APP na Bacia do Ribeirão do Jacú nos anos de 2002 e 2011 . Valores em porcentagem (\%). Cd: Corpo d'água; M: Mata; R: Reflorestamento; P: Pastagem; Cp: Cultura permanente; Ct: Cultura temporária; Ci: Cultura irrigada; E: Erosão Ac: Área construída.

Figure 8 - Land use at PPA at Ribeirão do Jacú watershed at 2002 and 2011. Cd: Water body; M: Forest; R: Reforest; P: Pasture; Cp: Permanent agriculture; $\mathrm{Ct}$ : Temporary agriculture; $\mathrm{Ci}$ : Irrigated agriculture; E: Erosion; Ac: Constructed area.
Embora a APP apresentar-se preservada em 52,58\% (208,80 ha) em 2002, este cenário está longe de ser adequado perante a legislação florestal vigente. Este fato se torna ainda mais preocupante quando se identifica um avanço de diferentes culturas e áreas de pastagens em locais que deveriam ser de preservação permanente. Entre 2002 e 2011 
ocorreu a supressão de $12,58 \%$, correspondente a diminuição de 49,95 ha da mata natural que compõe a área essencial para a manutenção dos recursos hídricos.

As áreas de pastagens são as que mais adentram nas APPs, representando 33,07\% (131,31 ha) em 2002 e 36,22 (143,82 ha) em 2011, perfazendo uma variação absoluta de 12,51 ha. Áreas de pastagem, por caracterizarem-se pela vegetação rasteira e de porte baixo, minimizam o efeito de "filtro" de proteção aos recursos hídricos em comparação com a vegetação natural, além de potencializar os processos erosivos que resultam em assoreamentos de corpos hídricos e compactam o solo, diminuindo assim o armazenamento de água e ar entre suas partículas, diminuindo também sua fertilidade.

Nas APPs, as classes que compõem a agricultura (cultura permanente, cultura temporária e cultura irrigada), juntas, representam um total de 12,60\% (50,04 ha) da APP em 2002 e 15,49\% (61,47 ha) em 2011, resultando em variação absoluta positiva de 11,43 ha. É possível identificar através dos números a tendência do avanço dessas culturas em áreas protegidas. Dentre elas, a mais representativa é a cultura permanente (com diferença percentual positiva de $2,02 \%$ e variação absoluta de 8,1 ha entre os anos de 2002 e 2011), seguida pela cultura temporária (com diferença percentual positiva de $0,82 \%$ e variação absoluta de 3,24 ha entre os anos de 2002 e 2011) e por fim, a cultura irrigada (se mostrando presente apenas em 2011, porém ainda pouco representativa, com diferença percentual de 0,05 e variação absoluta de 0,18 ha).

Também foi possível observar que a Bacia do Ribeirão do Jacú apresentou um expressivo avanço do reflorestamento que, embora represente uma menor ocupação em APP do que as outras atividades já mencionadas, obteve uma diferença percentual positiva de $6,82 \%$ entre os anos de 2002 e 2011. Esse número torna-se ainda mais preocupante quando observada a variação absoluta, que representa 27,09 ha (0,54 ha em 2002 e 27,63 ha em 2011) em área que deveria estar recoberta por vegetação natural protegida, sabendo que a disponibilidade de água disponível no solo e subsolo diminuem quando ocorre a substituição de vegetação natural, que são adaptadas ao local, por uma monocultura de reflorestamento.

Como pode ser observado em ambos os mapas gerados (Figuras 9 e 10), há grande ocupação antrópica em áreas que deveriam estar ocupadas por mata ciliar. A ocupação de locais de APP torna-se mais preocupante em rios de primeira ordem, onde encontram-se as nascentes, por serem locais de grande fragilidade e de suprimento aos corpos d'água, sendo prioritária para garantir a qualidade $\mathrm{e}$ quantidade ao longo de toda a bacia. A preservação dessas áreas consiste em, além da manutenção da vegetação natural ao entorno delas, cuidados especiais no manejo do solo para diminuir a velocidade das enxurradas e aumentar a infiltração de água no solo para o abastecimento das nascentes, prevenção contra descargas de esgotos no curso dos rios, bem como outros cuidados para evitar qualquer tipo de poluição das águas.

A caracterização e avaliação ambiental de uma região permite a identificação da complexidade do ecossistema diante da dinâmica de sua ocupação e vulnerabilidade, permitindo, assim, um melhor proveito do uso da terra de forma sustentável e a gestão de oportunidades de acordo com a realidade local.

Desta maneira, torna-se imprescindível compreender a dinâmica local e regional para tornar possível a compatibilização do desenvolvimento socioeconômico com a proteção e recuperação da zona de afloramento do SAG.

A região de maior vulnerabilidade da Bacia do Ribeirão do Jacú, por suas características pedológicas, é a localizada à sua margem direita, por caracterizar uma área de solos formados por arenitos, em contraponto com sua margem esquerda com formação basáltica. Assim, medidas conservacionistas são mais urgentes em áreas de maior vulnerabilidade em áreas de recarga dos recursos hídricos subterrâneos para prover descarga adequada às nascentes que, posteriormente, irão suprir todo o curso de água da bacia. 


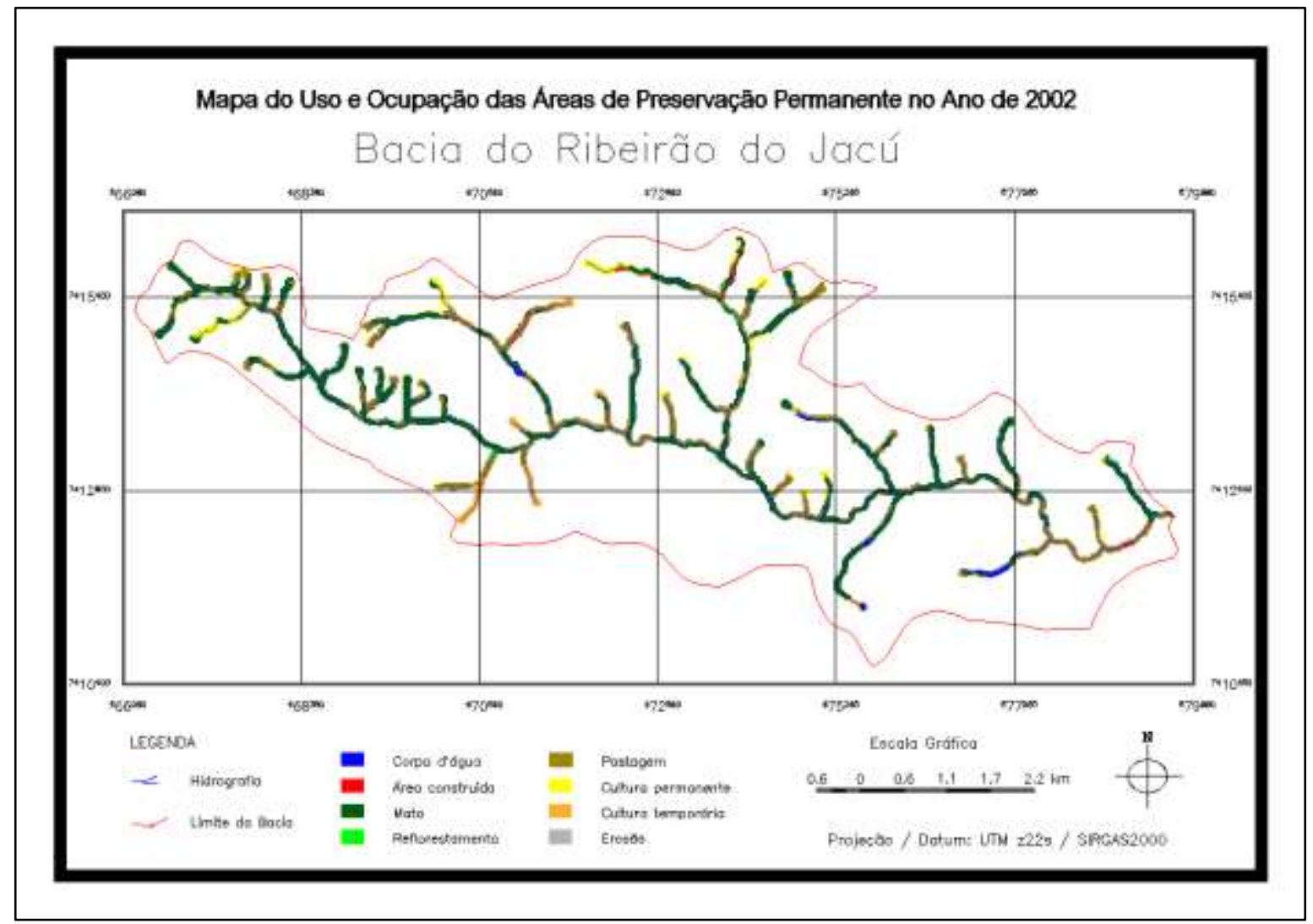

Figura 9 - Uso da terra em APP na Bacia do Ribeirão do Jacú no ano de 2002

Figure 9 - Land use at PPA at Ribeirão do Jacú watershed in 2002

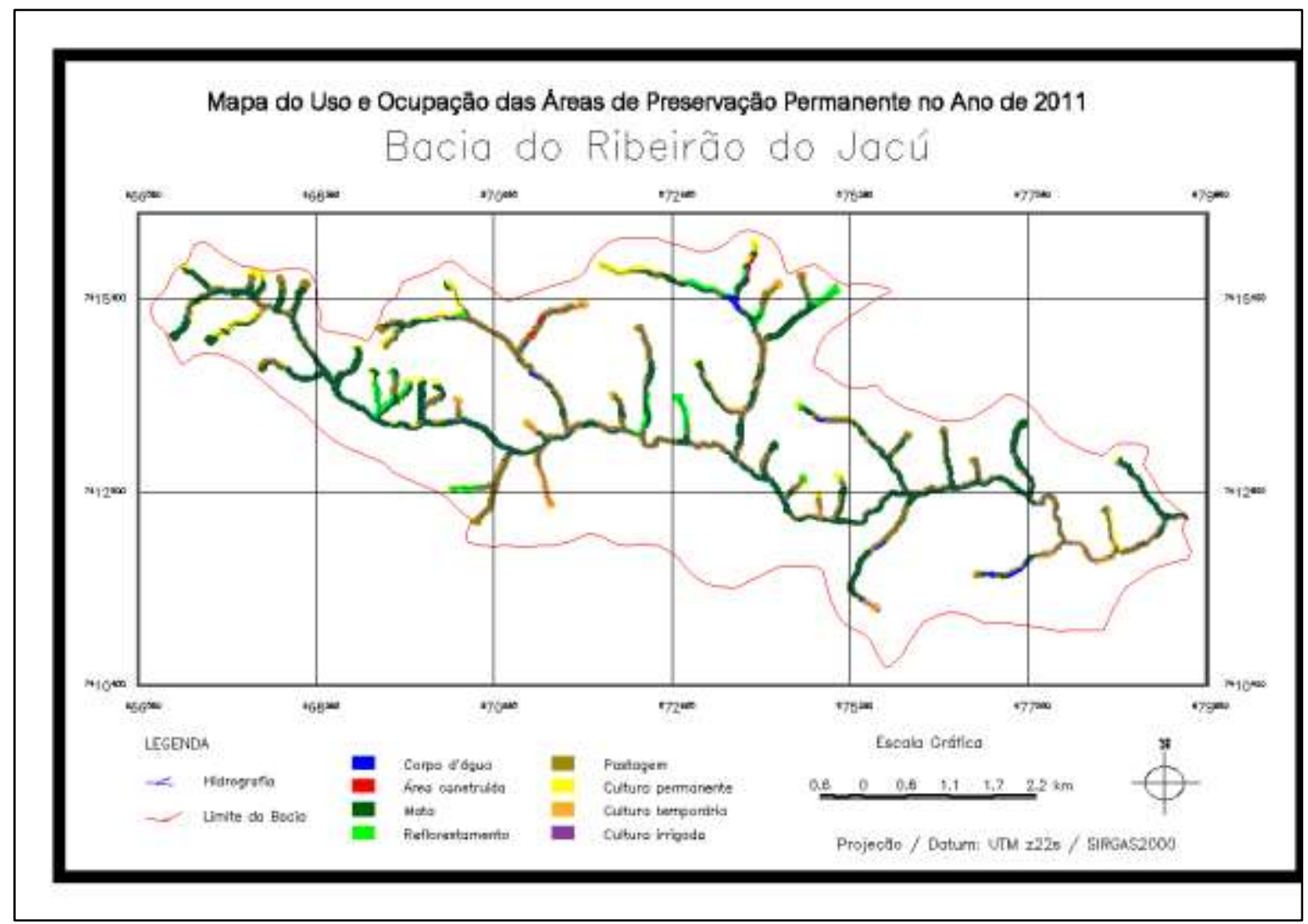

Figura 10 - Uso da terra em APP na Bacia do Ribeirão do Jacú no ano de 2011

Figure 10 - Land use at PPA at Ribeirão do Jacú watershed in 2011 
Considerando que as culturas irrigadas utilizam quantidades significativas de água e agroquímicos, se faz necessário o incentivo de práticas agrícolas adequadas, visando à proteção do SAG. Neste cenário, é importante considerar que a produção agrícola só é compreendida como positiva se os projetos de irrigação tiverem sustentabilidade econômica, social e ambiental, ou seja, se forem economicamente viáveis, socialmente responsáveis e ambientalmente sustentáveis. Esses ideais são claramente defendidos na Política Nacional de Irrigação (Lei ${ }^{\circ}$ 12.787, de 11 de janeiro de 2013).

Em visita de campo, pode-se verificar o uso de técnicas por parte dos produtores rurais que propiciam um manejo conservacionista e sustentável dos recursos naturais na área de estudo. Entre elas, destacam-se sistemas de rotação entre as culturas de milho e soja, que diminuem a exaustão do solo, além de técnica de plantio direto, que evita a mobilização do solo e cria um novo ambiente ecológico. Por outro lado, também foram verificados pontos negativos na bacia, como o descarte inadequado de embalagens de produtos agrícolas em torno dos corpos d'água, destinação incorreta de resíduos sólidos à beira de corpos d'água e possíveis pontos de eutrofização da água com clara alteração na cor da água.

A APA Corumbataí-Botucatu-Tejupá foi criada com o objetivo de proteger a fauna, flora, atributos geológicos e geomorfológicos e o patrimônio arqueológico e cultural da região. Segundo Albuquerque et al. (2010), uma área semelhante poderia ser protegida citando a proposta de Áreas de Intervenção, conforme preconizado na Lei Estadual no 9.866/97 que dispõe sobre a proteção e recuperação das bacias hidrográficas dos mananciais de interesse regional do Estado de São Paulo. Segundo os autores, o município de Tejupá possuiria áreas de ocupação dirigida (AOD), contando com subáreas de proteção especial. O Código Florestal, em sua versão atual (Lei $n^{\circ} 12.651$, de 25 de maio de 2012) como na anterior (Lei $n^{\circ}$ 4.771, de 15 de setembro de 1965) apresentam proteção para as APPs, com intuito, dentre outros, a conservação dos recursos hídricos.

Desta forma, existem uma série de mecanismos legais que não só permitem como também obrigam a criação manejos e práticas especiais para que sejam desenvolvidas atividades econômicas em consonância com os interesses sociais e ambientais. Isso constata o reconhecimento dessas áreas como servidoras ecossistêmicas.

Compete aos órgãos locais que atuam junto aos recursos hídricos, ao meio ambiente e a agricultura fazer uso de informações como as desse trabalho para direcionar o uso e ocupação da terra, difundir novas técnicas e multiplicar o conhecimento gerado em universidades, institutos de pesquisa e programas de extensão governamentais.

\section{CONCLUSÕES}

Através da classificação foi identificada a modificação do uso da terra no período de 2002 a 2011. As classes que apresentaram aumento em 2011 em relação a 2002 foram: Reflorestamento (R) com 392,42\% e Área construída (Ac) com 8,89\%. Já as classes que apresentaram diminuição neste período foram: Corpos d'água (Cd) com -12,43\%, Mata (M) com -24,16\%, Pastagem (P) com -2,66\%, Cultura permanente (Cp) com -7,08\%, e Cultura temporária $(\mathrm{Ct}) \mathrm{com}-10,01 \%$. Foi detectado o surgimento de uma nova classe de uso do solo no Ribeirão do Jacú em 2011, Culturas irrigadas $(\mathrm{Ci})$, ocupando 95,76 ha $(2,60 \%)$ da área da bacia em 2011. Já a classe Erosão (E) detectada em 2002 já não se encontra presente na área de estudo em 2011.

Visando a proteção do SAG, fica evidente a necessidade do disciplinamento da ocupação territorial nessas áreas, principalmente pelos conflitos de usos da terra em APP. São perceptíveis os conflitos ambientais entre produção agrícola e conservação local na Bacia do Ribeirão do Jacú, apresentando diversos pontos sem a devida proteção das nascentes, cursos do rio e represas.

Diversos pontos considerados como APP estão ocupados por pastagens ou diferentes culturas em 2011. A supressão das matas ripárias ou de fragmentos acompanham o intenso avanço do reflorestamento para fins econômicos e, apesar das diminuições das áreas ocupadas com P, Cp e Ct em 2011, a 
presença dessas atividades aumentou nas APPs.

O uso de imagens de satélite e técnicas de geoprocessamento foram ferramentas importantes para a classificação do uso da terra por monitorar as mudanças ocorridas na bacia no período de 2002 a 2011.

Os mapas gerados são úteis como instrumento de gestão e planejamento da área de estudo por abordar tanto o contexto de natureza agrícola, no que se refere a evolução do uso da terra, como o ambiental, para fiscalização e recuperação de APPs. Também são úteis

\section{REFERÊNCIAS}

AGÊNCIA NACIONAL DE ÁGUAS - ANA. Conjuntura dos Recursos Hídricos no Brasil: informe 2014. Brasília: ANA, 2015.

AGÊNCIA NACIONAL DE ÁGUAS - ANA. Panorama da qualidade das águas subterrâneas no Brasil.2007. In: CONEJO, J. G. L.; COSTA, M. P.; ZOBY, J. L. G. (Org.). Caderno de Recursos Hídricos v.5. Brasília: ANA, 2007.

ALBUQUERQUE FILHO, J. L. et al. Plano de desenvolvimento e proteção ambiental da área de afloramento do Sistema Aquífero Guarani no Estado de São Paulo: proposta preliminar. In: XVI Congresso Brasileiro de Águas Subterrâneas e XVII Encontro Nacional de Perfuradores de Poços. Anais... São Luís - MA, 2010, 12p.

ALBUQUERQUE FILHO, J. L. et al. Sistema Aquífero Guarani: subsídios ao plano de desenvolvimento e proteção ambiental da área de afloramento do Sistema Aquífero Guarani no Estado de São Paulo. São Paulo: IPT, 2011, $102 \mathrm{p}$.

BEZERRA, M. do C. L.; VEIGA, J. E. Agricultura sustentável: subsídios à elaboração da agenda 21 brasileira. Brasília: Ministério do Meio Ambiente, Instituto Brasileiro do Meio Ambiente e dos Recursos Naturais Renováveis; Consórcio Museu Emílio Goeldi. 2000, 190 p.

BORGES, L. A. C. Aspectos técnicos e legais que fundamentam o estabelecimento das Áreas de Preservação Permanente (APP). 2008. 193f. Tese (Doutorado) Curso de Engenharia Florestal, Universidade Federal de Lavras, Lavras-MG, 2008.

BRASIL. Lei $n^{0}$ 4.771, de 15 de setembro de 1965. Institui o novo Código Florestal. Legislação Federal. Brasí lia, DF: Presidência da República, 1995. Disponível em: <http://www.planalto.gov.br/ccivil_03/leis/L4771.htm>. Acesso em: 16 de março de 2016. como instrumento de definição de prioridades na resolução de problemas e prover soluções com programas que incentivem os agricultores a desenvolver ações conservacionistas e evitar futuros impactos aos recursos hídricos, em especial, os subterrâneos.

Os resultados do estudo contribuem para se atingir uma base técnica de conhecimento e discussão de uma adequada gestão de áreas de afloramento do SAG ao ajudar a dirigir as áreas de intervenção por complementar os dados já existentes aos planos de proteção ao SAG.

BRASIL. Lei $\mathbf{n}^{\mathbf{0}} \mathbf{1 2 . 6 5 1}$, de 25 de maio de 2012. Dispõe sobre a proteção da vegetação nativa. Legislação Federal. Brasília, DF: Presidência da República, 2012. Disponível em: <http://www.planalto.gov.br/ccivil_03/_Ato20112014/2012/Lei/L12651.htm> Acesso em: 25 de janeiro de 2013.

BRASIL. Lei $\mathbf{n}^{\circ}$ 12.787, de 11 de janeiro de 2013. Dispõe sobre a Política Nacional de Irrigação. Legislação Federal. Brasília, DF: Presidência da República, 2013. Disponível em: <http://www.planalto.gov.br/ccivil_03/_Ato2011-2014/2013/Lei/L12787.htm> Acesso em: 25 de maio de 2013.

CAMARA, G. et al. SPRING: Integrating remote sensingand GIS by object-oriented data modeling. Computers \& Graphics. Elmsford, Computers \& Graphics, v. 20, n. 3, p. 395-403, 1996.

CHRISTOFIDIS, D. A água e a crise alimentar. In: Encontro das águas, 1997. Fortaleza: Instituto Interamericano de Cooperação para a Agricultura - IICA, 1997, 14p. Disponível em: <http://www.iica.org.br/Aguatab/ Demetrios\%20Christofidis/P2TB01.htm>. Acesso em: 02 de setembro de 2012.

COELHO, C. A. S.; CARDOSO, D. H. F.; FIRPO, M. A. F. Precipitation diagnostics of an exceptionally dry event in São Paulo, Brazil. Theoretical and Applied Climatology, [s.l.], p.1-16, 2015. Springer Science + Business Media. http://dx.doi.org/10.1007/s00704-015-15409. CONGALTON, R. G.; GREEN, K. Assessing the accuracy of remotely sensed data: principles and practices. New York: Lewis Publishers, 1998. 137p.

DOWBOR, L. Economia das águas. In: DOWBOR, L.; TAGNIN, R. A. (Org.). Administrando a água como se fosse importante. 1 ed. São Paulo: SENAC, 2005, p. 2736. 
FAIL, J. L.; HAINES, B. L.; TODD, R. L. Riparian forest communities and their role in nutrient conservation in an agriculture watershed. American Journal of Alternative Agriculture, Cambridge, v.2, p.114-121, 1987.

HEALY, R. W. Estimating groundwater recharge. Cambridge: Cambridge University Press, 2010. 245p.

HIRATA, R. C. A. Fundamentos e estratégias de proteção e controle da qualidade das águas subterrâneas: estudo de casos no Estado de São Paulo, São Paulo. 1994. 195 f. Tese (Doutorado) - Curso de Recursos Minerais e Hidrogeologia, Instituto de Geociências, Universidade de São Paulo - USP, São Paulo, 1994.

INSTITUTO BRASILEIRO DE GEOGRAFIA E ESTATÍSTICA - IBGE. Manual técnico de uso da terra. 3. ed. Rio de Janeiro, 2013.

INSTITUTO DE PESQUISAS TECNOLÓGICAS DO ESTADO DE SÃO PAULO - IPT. Mapa Geológico do Estado de São Paulo. Escala 1: 500.000. São Paulo, 1974.

IRITANI, M. A.; EZAKI, S. As águas subterrâneas do Estado de São Paulo. São Paulo: Secretaria do Estado do Meio Ambiente- SMA, 2008. 103p.

KÖPPEN, W. Die Klimate der Erde. Grundriss der Klimakunde. Walter de Gruyter, Berlin, 1923.

LANDIS, J. R.; KOCH, G. G. The Measurement of Observer Agreement for Categorical Data. Biometrics, v. 33, n. 1, p. 159-174, 1977.

LEPSCH, I. F.; BELLINAZZI, R.; BERTOLINI, D.; ESPÍNDOLA, C. R. Manual para levantamento utilitário do meio físico e classificação de terras no sistema de capacidade de uso. $5^{\text {a }}$ Aproximação. Campinas: Sociedade Brasileira de Ciência do Solo, 1991. 175p.

LIMA, W. de P., ZAKIA, M. J. B. Hidrologia de matas ciliares. In: RODRIGUES, R. R.; LEITÃO FILHO, H. de F. (Org.). Matas ciliares: conservação e recuperação. 2 ed. 2. reimpr. - São Paulo: Editora da Universidade de São Paulo, FAPESP, 2009. p. 91 - 99.

LIMA, W. P.; ZAKIA, M. J. B. O papel do ecossistema ripário. In: LIMA, W. P.; ZAKIA, M. J. B. (Org.). As florestas plantadas e a água: implementando o conceito da microbacia hidrográfica como unidade de planejamento. São Carlos: RiMa, 2006. p. 77-87.

LOWRANCE, R. et al. Water quality functions of riparian forest buffers in Chesapeak Bay watersheds. Environmental Management, New York, v.21, p.687-712, 1997.

LOZANO, M. R. L. Geoecologia da paisagem na avaliação do uso dos recursos hídricos da parte inicial da
Bacia do Ribeirão das Posses. 2013, 74f. Dissertação (Mestrado). Programa de Irrigação e Drenagem. Universidade Estadual Paulista - Faculdade de Ciências Agronômicas, Botucatu, 2013.

LUCAS, M.; WENDLAND, E. Recharge estimates for various land uses in the Guarani Aquifer System outcrop area. Hydrological Sciences Journal, [s.1.], p.1-10, 2016. Informa UK Limited. http://dx.doi.org/10.1080/02626667.2015.1031760.

NAIMAN, R. J.; DÉCAMPS, H. The ecology of interfaces: riparian zones. Annual Review Ecological System, v.28, p.621-658, 1997.

OLIVEIRA, J. B. et al. Mapa Pedológico do Estado de São Paulo. 1:500.000. Campinas: IAC/EMBRAPA/FAPESP, 1999.

REBOUÇAS, A. C. Água subterrânea. In. REBOUÇAS, A. C.; BRAGA, B.; TUNDISI, J. G. (Org.). Águas doces no Brasil: capital ecológico, uso e conservação. $3^{\circ}$ ed. São Paulo: Escrituras, 2006, p.111-141.

RODRIGUEZ, A. C. M. Sensoriamento remoto e geoprocessamento aplicados na análise da legislação ambiental no município de São Sebastião-SP. 2005, $201 \mathrm{f}$. Dissertação (Mestrado) Curso de Geografia. Universidade de São Paulo, São Paulo, 2005.

ROSS, J. L.S.; MOROZ, I. C. Mapa geomorfológico do Estado de São Paulo. Revista do Departamento de Geografia, São Paulo, n.10, 1996, p.41-56.

SÃO PAULO (ESTADO). Lei n ${ }^{\circ} 9.866$, de 28 de novembro de 1987. Proteção e recuperação das bacias hidrográficas dos mananciais de interesse regional do Estado de São Paulo. Legislação Estadual. Disponível em: <http://governo-sp.jusbrasil.com.br/legislacao/170520/lei-9866-97> Acesso em: 31 de janeiro de 2014.

SÃO PAULO (ESTADO). Decreto 20.960, de 08 de jnho de 1983. Declara área de proteção ambiental a regões situadas em diversos municípios, dentre os quais Corumbataí, Botucatu e Tejupá. Legislação Estadual. São Paulo, SP, 1983. Disponível em: <http://www.ambiente.sp.gov.br/legislacao/decretos/decreto-estadual-n20-960/>. Acesso em: 31 de janeiro de 2014.

SCANLON, B. R. et al. Impact of land use and land cover change on groundwater recharge and quality in the southwestern US. Global Change Biol, [s.1.], v. 11, n. 10, p.1577-1593, 2005. Wiley-Blackwell. http://dx.doi.org/10.1111/j.1365-2486.2005.01026.x

SOUZA, M. A. S. et al. Avaliação da variabilidade espacial do atributo físico resistência a penetração em diferentes regiões do cafeeiro e sistema de manejo empregado em solo de cerrado de Minas Gerais. In: VII Encon- 
Classificação do uso da terra em área de afloramento do Sistema Aquífero Guarani entre 2002 e 2011: o caso da Bacia do Ribeirão do Jacú, Tejupá/SP

tro Latino Americano de Iniciação Científica e IV Encontro Americano de Pós-Graduação São José dos Campos., Anais... São José dos Campos: Universidade do Vale do Paraíba, 2004, p. 1505 - 1508.

TANIKAWA, D. H.; MANZIONE, R. L. Análise da correlação entre a resposta espectral da cultura de eucalipto e oscilação de níveis freáticos em área de recarga do Sistema Aquífero Guarani. In: Congresso de Iniciação Científica da Unesp, XXIII, 2011, São Pedro. Anais... São Pedro: UNESP, 2011.

TAVARES FILHO, J. et al. Resistência do solo à penetração e desenvolvimento do sistema radicular do milho
(Zea mays) sob diferentes sistemas de manejo. Revista Brasileira Ciência do Solo, Viçosa, v. 25, n.3, p.725730, 2001.

TUNDISI, J. G.; MATSUMURA-TUNDISI, T. Limnologia. São Paulo: Oficina de Textos, 2008. 631p.

VAERET, L. et al. A modelling study of the effects of land management and climatic variations on groundwater inflow to Lake St Lucia, South Africa. Hydrogeol J, [s.1.], v. 17, n. 8, p.1949-1967, 2009. Springer Science + Business Media. http://dx.doi.org/10.1007/s10040009-0476-5. 